\section{Kroniek rechtspraak strafrecht ${ }^{\mathrm{I}}$}

\author{
Mw.mr.dr.W.L.J.M.Duijst ${ }^{2}$
}

In deze kroniek zijn de bekende thema's van het gezondheidsstrafrecht, zoals beroepsgeheim, dood door schuld, hiv, alternatieve genezers en handelen rond het levenseinde weer aanwezig. Uitspraken die in juridische zin opzienbarend waren zijn er het afgelopen jaar niet geweest, wel uitspraken die gezien hun 'exotische' karakter of de maatschappelijke relevantie de aandacht van de media trokken.

1 BEROEPSGEHEIM

Savanna

Het verhaal van Savanna mag bekend worden verondersteld. In deze zaak is een gezinsvoogd aangeklaagd voor dood door schuld, vanwege het feit dat zij op de hoogte was (of had moeten zijn) van de misstanden rondom Savanna en desondanks onvoldoende adequaat is opgetreden. In het kader van dit justitieel onderzoek wordt een consultatiebureaudossier van de Stichting thuiszorg in beslag genomen om zicht te krijgen op het aantal en soort contacten tussen de gezinsvoogd en het gezin van Savanna. De Stichting thuiszorg doet op grond van artikel 552a Wetboek van Strafvordering (Sv) beklag over de inbeslagneming. Ondanks toestemming van de moeder, die veroordeeld is voor de doodslag op Savanna (Rb. Den Haag 2I juni 2006, LJN AT7856, zaaknr. 09/753550-04) en de toestemming van de gezinsvoogd, wordt het beklag gehonoreerd. De Hoge Raad is van mening dat de inbeslagneming ontoereikend gemotiveerd is. De Hoge Raad neemt daarbij in aanmerking dat het hier niet gaat om een tegen een verschoningsgerechtigde bestaande verdenking en daarnaast acht de Raad de aard en de omvang van de gegevens die vrij komen bij het doorbreken van het verschoningsrecht en de omstandigheid dat het gaat om een verdenking op grond van artikel 307 Wetboek van Strafrecht (Sr; dood door schuld) van belang. De rechtbank heeft onvoldoende blijk gegeven dat voldoende onderzoek is verricht naar de vraag of de gegevens ook op andere wijze beschikbaar kunnen komen. De Hoge Raad vernietigt de beschikking van de rechtbank.

Rb. Den Haag 23 augustus 2005, LJN AX0325, zaaknr. RK 05/I882 en HR 9 mei 2006, TvGR 2006/47 (m.nt. W.R. Kastelein); JOL 2006/308. W.R. Kastelein, 'Is spreken nog zilver en zwijgen goud?', NJB 2006, p. $1570-1572$.

\section{Dagboek}

Een minderjarige verstandelijk gehandicapte jongen wordt verdacht van het plegen van zedendelicten (art. 246-247 Sr) tegen een zesjarig meisje. In het kader van het justitieel onderzoek wordt een 'dagboek' dat aan de moeder van de jongen toebehoort en dat zich bij de advocaat van de jongen bevindt, in beslag genomen. De advocaat doet op grond van artikel 552a Sv beklag tegen de inbeslagneming. De Hoge Raad is met de rechtbank van mening dat ook de informatie die de moeder verschaft over haar gehandicapte zoon heeft te gelden als wetenschap die aan de advocaat in het kader van zijn beroepsuitoefening is toevertrouwd. De stelling dat onder het verschoningsrecht alleen brieven en geschriften vallen die door de verschoningsgerechtigde zijn geschreven vindt geen steun in het recht. De Hoge Raad verwerpt het beroep ingesteld door de officier van justitie.

HR 24 januari 2006, JOL 2006/48; NJ 2006/I09.

Met deze beide uitspraken lijkt de Hoge Raad weer zijn oude spoor ten aanzien van het verschoningsrecht te volgen. Wat aan de verschoningsgerechtigde is toevertrouwd moet ruim worden geïnterpreteerd, de verschoningsgerechtigde bepaalt in principe zelf wat onder zijn verschoningsrecht valt en een inbreuk door het strafrecht wordt slechts getolereerd in zeer uitzonderlijke gevallen, bijvoorbeeld als de verschoningsgerechtigde wordt verdacht van een ernstig strafbaar feit. 
2 SCHULD AAN OVERLIJDEN/DOODSLAG

\section{Ambulancebroeder}

De hulp van een ambulance wordt ingeroepen voor een man die acute psychiatrische verschijnselen vertoont. De ambulancebroeder heeft als werkdiagnose dat de acute psychiatrische verschijnselen zijn veroorzaakt door het gebruik van verdovende middelen. De man wordt in verband met agressief gedrag overgebracht naar het politiebureau ten einde hem aldaar te presenteren aan de psychiater van de crisisdienst.

De man komt acuut te overlijden aan een niet onderkend cocainnedelirium. De ambulancebroeder wordt vervolgd voor het opzettelijk in hulpbehoevende toestand achterlaten van de man. De rechtbank is van mening dat de ambulancebroeder een inschattingsfout heeft gemaakt, maar dat van opzettelijk in hulpbehoevende toestand achterlaten geen sprake is. De rechtbank komt tot vrijspraak.

Rb. Amsterdam 27 oktober 2005, LJN AU5098, zaaknr. I3/45I280-05.

\section{Ambulancechauffeur}

Een acuut uitgerukte ambulance begeeft zich met zwaailicht en sirene naar de plaats waar hulp gevraagd is. Volgens de analyse achteraf rijdt de ambulancechauffeur $\mathrm{I} 4 \mathrm{O} \mathrm{km} / \mathrm{uur}$ (waar $8 \mathrm{o} \mathrm{km} / \mathrm{uur}$ is toegestaan), bij het naderen van een kruising mindert hij de snelheid tot 95-II5 km/uur en rijdt door rood. Bij deze manoeuvre ontstaat een aanrijding waardoor een inzittende van de andere auto, een kind, komt te overlijden. De ambulancechauffeur wordt vervolgd voor het veroorzaken van dood door schuld in het verkeer (art. 6 Wegenverkeerswet 1994 (WVW I994)), subsidiair het veroorzaken van gevaar of hinder op de weg (art. 5 WVW i994). De rechtbank acht de ambulancechauffeur schuldig aan overtreding van artikel 6 WVW 1994. Een aantal overwegingen van de rechtbank is opmerkelijk. Het bewijs dat de chauffeur te hard heeft gereden wordt gebaseerd op getuigenverklaringen en de impact van de aanrijding. De te hoge snelheid blijkt niet uit de gegevens van de in de ambulance aanwezige black box en evenmin uit de verklaring van de ambulancebroeder, die als onwaar wordt afgedaan. Tevens stelt de rechtbank dat de opleiding van ambulancebroeders niet gericht is op het met hoge snelheid deelnemen aan het tegen- woordig drukke verkeer en dat er geen interne richtlijnen zijn over hoe deel te nemen aan het verkeer na een AI-melding (melding met het verzoek om acute hulp). In de opleiding wordt echter uitgebreid aandacht besteed aan het rijden met hoge snelheid met zwaailicht en sirene en de daaraan klevende gevaren en verantwoordelijkheden. Bovendien bestaan er landelijke richtlijnen voor ambulancechauffeurs voor het besturen van voertuigen onder deze omstandigheden.

De rechtbank legt een werkstraf op van I2O uren, vervangende hechtenis van zestig dagen en een voorwaardelijke ontzegging van de rijbevoegdheid voor de duur van twaalf maanden, met een proeftijd van twee jaar.

Rb. Arnhem 23 juni 2006, LJN AX9255, zaaknr. 05/650696-06. J.A.J. Besseling e.a., Leerboek ambulancechauffeur, SOSA 2003. St. ontwikkeling vakopleiding ambulancehulpverlening, Rijtechnische richtlijnen ambulancezorg 2003.

\section{Te heet badwater}

Een medewerkster van een zorgcentrum verzuimt bij een badbeurt van een meervoudig gehandicapte bewoonster de temperatuur van het badwater te controleren. Het aflezen van de temperatuur op een aanwezig display wordt achterwege gelaten en de temperatuur wordt niet fysiek vastgesteld. De bewoonster loopt door te heet badwater ernstige brandwonden op en komt een week later te overlijden. De medewerkster wordt vervolgd voor dood door schuld. De rechtbank legt een werkstraf op van honderd uur, en vervangende hechtenis van vijftig dagen. De rechtbank acht het opleggen van een straf noodzakelijk in verband met generale preventie. Bij de straf is rekening gehouden met de jeugdige leeftijd van de verdachte en het feit dat zij publiekelijk verantwoording heeft moeten afleggen voor haar handelen.

Rb. Breda 6 april 2006, GJ 2006/6o.

\section{Charlotte Floor}

Een cardioloog gebruikt voor een cardiologische ingreep bij een zeven maanden oude baby een katheter die op onjuiste wijze is afgesneden. De katheter doorboort een cardiaal vat, waardoor het meisje overlijdt. Tevens blijkt de cardioloog bij strafrechtelijk onderzoek kinderporno in zijn bezit te hebben. 
De cardioloog wordt vervolgd voor primair doodslag, subsidiair dood door schuld en daarnaast voor het in bezit hebben van kinderporno. Het hof volgt de rechtbank in zijn oordeel dat het subsidiair ten laste gelegde feit, doodslag, en het tweede feit beide kunnen worden bewezen en veroordeelt de verdachte tot 180 dagen hechtenis, waarvan I29 dagen voorwaardelijk, met een proeftijd van twee jaar, een werkstraf van 240 uur, vervangende hechtenis van I2o dagen en een voorwaardelijke ontzetting uit het beroep van arts voor drie jaar met als bijzondere voorwaarde dat de arts niet werkzaam mag zijn als kinderarts en/of cardioloog. De pornobanden worden onttrokken aan het verkeer en een teruggave van het rapport van de commissie/Bühler ${ }^{3}$ wordt gelast.

Hof Arnhem I2 oktober 2005, TvGR 2006/9.

\section{Lucia de B.}

De zaak van Lucia de B. heeft al geruime tijd de aandacht van de media. Het Hof Den Haag heeft op I8 juni 2004 Lucia de B. veroordeeld voor het om het leven brengen van een aantal van haar, soms zeer jeugdige, patiënten die zij als verpleegkundige verzorgde. Het hof baseerde zijn veroordeling voornamelijk op zogeheten schakelbewijs. Het hof was van mening dat de statistische kans dat een verpleegkundige betrokken zou kunnen zijn bij de zorg van zoveel patiënten die tijdens dat zorgproces overlijden uitermate klein was. Het hof legde hiervoor een levenslange gevangenisstraf in combinatie met terbeschikkingstelling (tbs) met dwangverpleging op.

Tegen de uitspraak van het hof is verdachte in cassatie gekomen. Het cassatieberoep richt zich onder andere op het gebruik van het schakelbewijs en het opleggen van levenslange gevangenisstraf in combinatie met tbs met dwangverpleging. De Hoge Raad conformeert zich wat het gebruik van het schakelbewijs betreft aan het oordeel van het hof. De Hoge Raad is echter van mening dat gezien het doel en de aard van levenslange gevangenisstraf, namelijk het voorkomen van een terugkeer in de maatschappij, deze straf niet kan worden opgelegd met tbs met dwangverpleging. De Hoge Raad vernietigt de uit-

3. Het Rapport van de commissie-Bühler werd op verzoek van de Inspectie voor de Volksgezondheid opgesteld inzake de communicatieproblemen op de afdeling van de arts. Het rapport was bedoeld voor intern gegebruik. spraak en verwijst de zaak naar het Hof Amsterdam. Het Hof Amsterdam veroordeelt Lucia de B., die inmiddels in detentie een hersenbloeding heeft gehad, tot levenslange gevangenisstraf.

Onder statistici is er veel onenigheid over de betrouwbaarheid van het statistisch bewijs in deze zaak. De zaak Lucia de B. is om die reden door een statisticus aangemeld bij de commissie-Postumus. ${ }^{4}$ De zaak Lucia de B. wordt vervolgd?

HR I4 maart 2006, LJN AU 5496, zaaknr. 0343I/o4, Hof Amsterdam I3 juli 2006, LJN AY3864, zaaknr. 23-00I403-06.

\section{ALTERNATIEVE GENEZERS}

\section{Magnetiseur}

Een magnetiseur/alternatieve genezer heeft vier meisjes onder de leeftijd van I6 jaar uit een gezin onder behandeling. De moeder van de meisjes gelooft heilig in de behandeling van de alternatieve genezer en geeft hem volledig de vrije hand. Dit leidt ertoe dat de alternatieve genezer feitelijk deel gaat uitmaken van het gezin. Vanuit die positie mishandelt hij de meisjes en pleegt ontuchtige handelingen met hen. Dit alles met medeweten van de moeder. De man wordt vervolgd voor het plegen van ontuchtige handelingen met iemand onder de leeftijd van i6 jaar, voor aanranding van de eerbaarheid en voor mishandeling. De rechtbank legt een gevangenisstraf van vier jaar op en wijst de vorderingen van de benadeelde partijen ter grootte van $€ 3.84$ o per kind toe. Aan de omstandigheid dat de alternatieve genezer de feiten heeft gepleegd in de uitoefening van zijn beroep, besteedt de rechtbank geen aandacht. De moeder wordt vervolgd voor medeplegen van genoemde feiten.

$\mathrm{Rb}$. Utrecht 20 maart 2006, LJN AV5874 (magnetiseur). Rb. Utrecht 20 maart 2006, LJN AV5899, zaaknr. 16/604176-05 (moeder).

\footnotetext{
4. De commissie-Posthumus is ingesteld na de Schiedamse parkmoord en onderzoekt afgesloten moordzaken.
} 
Masseur/hypnotherapeut

Een masseur/hypnotherapeut pleegt ontuchtige handelingen met een cliënt. Hij wordt vervolgd voor het plegen van ontucht met misbruik van gezag (art. 249 lid 2 onder ${ }^{\mathrm{e}} \mathrm{Sr}$ ). Van belang bij de veroordeling is het feit dat de masseur/hypnotherapeut werkzaam is in de gezondheidszorg. Door het Hof Amsterdam wordt hij veroordeeld tot vijftien maanden gevangenisstraf, waarvan vijf maanden voorwaardelijk, met een proeftijd van twee jaar.

In cassatie wordt bestreden dat de masseur| hypnotherapeut werkzaam was in de gezondheidszorg. De Hoge Raad verwijst voor een uitleg van de term 'werkzaam in de gezondheidszorg' naar de Wet op de beroepen in de individuele gezondheidszorg (Wet BIG); gezondheidszorg heeft een ruimere betekenis dan het begrip geneeskunst. De Hoge Raad betoogt dat het ontbreken van de mogelijkheid om alternatieve genezers een tuchtrechtelijk verwijt te maken er bij de totstandkoming van de Wet BIG toe heeft geleid dat de strafbaarstelling van artikel 249 lid 2 Sr is uitgebreid met een strafbaarstelling voor werkers in de gezondheidszorg. De strafrechtelijke bescherming van artikel 249 Sr moet zich, aldus de Hoge Raad, ook tegen alternatieve genezers richten. De Hoge Raad laat de uitspraak van het hof in stand.

HR i7 januari 2006, JOL 2006/29; NJ 2006/89. Dit arrest is een vervolg op HR 2 december 2003, JOL 2003/632, NJ 2004/78.

\section{Macrobioot}

Een macrobiotisch adviseur behandelt een vrouw met baarmoederhalskanker. Hij adviseert haar een macrobiotisch dieet te volgen en ontraadt haar om allopathische artsen te raadplegen. De adviseur wordt vervolgd voor mishandeling. Het hof stelt dat de macrobiotisch adviseur een bijzondere zorgplicht had die ertoe had moeten leiden dat hij minder zijn weerstand tegen reguliere geneeskunst zou etaleren. Tevens had hij zijn cliënte beter moeten informeren over het feit dat geen enkele wetenschappelijk bewijs bestaat dat door middel van macrobiotiek alleen baarmoederhalskanker kan worden genezen. Het hof legt een gevangenis van zes maanden voorwaardelijk met een proeftijd van twee jaar op.

Hof Den Haag 27 maart 2006, GJ 2006/59. Verwijzing na HR I4 juni 2005, GJ 2005/76.
4 HIV

De vraag of het hebben van onbeschermd seksueel contact bij een positieve hiv-status een poging tot het toebrengen van zwaar lichamelijk letsel is, heeft - getuige de navolgende uitspraken - in de rechtspraak tot een eenduidig antwoord geleid. De onderstaande uitspraken verschillen wat betreft omstandigheden, maar niet wat betreft de strekking.

Hiv-I

Een hiv-besmette man heeft onbeschermd seksueel contact met anderen, zonder dat hij die personen op de hoogte had gebracht van zijn hiv-status. De man wordt vervolgd voor poging tot het toebrengen van zwaar lichamelijk letsel. Het hof oordeelt conform HR 25 maart 2003, NJ 2003/552 dat het hebben van onbeschermd seksueel contact bij een positieve hivstatus nog geen poging tot zwaar lichamelijk letsel oplevert. Eerst als sprake is van risicoverhogende factoren zoals een hoge virusload, seksueel contact met verhoogd risico, dwang bij het seksueel contact, de aanwezigheid van een andere seksueel overdraagbare aandoening (soa), de aanwezigheid van een verwonding bij een van de partners of het meerdere malen aangaan van contact met dezelfde partner, kan gesproken worden van een poging tot zware mishandeling. Het hof legt een gevangenisstraf op van twee jaar en I34 dagen. Bij de straf is rekening gehouden met het feit dat de redelijke termijn voor behandeling van de zaak is verstreken.

Hof Den Bosch 29 november 2005, LJN AU702I, zaaknr. 2O-000345-05. Vervolg op HR I8 januari 2005, TvGR 2005/6.

Hiv-2

Een hiv-positieve man, tevens lijdend aan syfilis, die als ongewenste vreemdeling in ons land verblijft, bijt een slachtoffer in de pink en slaat een ander slachtoffer in de nek en krabt vervolgens dit laatstgenoemde slachtoffer op de onderarm. Wanneer de man wordt aangehouden verzet hij zich met geweld tegen deze aanhouding. De rechtbank veroordeelt de man voor mishandeling, tweemaal gepleegd. De arts die de bijtwond van het eerste slachtoffer beoordeeld heeft kon niet met zekerheid vaststellen dat de man door de huid gebeten had. De virusload van de man kon niet 
worden vastgesteld omdat hij weigerde mee te werken aan het bloedonderzoek; hierdoor kon niet worden vastgesteld of er een verhoogde kans was op een hiv-besmetting. Dit laatste was mijns inziens gezien het gegeven dat de arts niet kon vaststellen dat door de huid heen gebeten was ook nauwelijks van belang. De rechtbank veroordeelt de man tot een gevangenisstraf van 308 dagen. Gezien het feit dat de man tot de dag van het vonnis in voorlopige hechtenis heeft doorgebracht, wordt hij onmiddellijk in vrijheid gesteld.

Rb. Leeuwarden 4 juli 2006, LJN AYoi88, zaaknr. I7/880I82-05 VEV.

Hiv-3

Een zwakzinnige man, die hiv-positief is, pleegt gedurende langere tijd ontucht met een minderjarige onder de leeftijd van I6 jaar en verkracht een kind jonger dan I2 jaar. De man wordt vervolgd voor de ontucht en de verkrachting en tevens voor een poging tot het toebrengen van zwaar lichamelijk letsel door het hebben van onbeschermd seksueel contact bij een positieve hiv-status. De rechtbank veroordeelt de man voor de beide seksuele delicten. Van de poging tot het toebrengen van zwaar lichamelijk letsel wordt hij vrijgesproken. De rechtbank veroordeelt de man tot een jaar gevangenisstraf en tbs met dwangverpleging.

Rb. Zutphen 27 december 2005, LJN AU8715, zaaknr. 06/460225-05.

Hiv-4

Een man met een positieve hiv-status heeft, samen met een andere man, gedurende een zeer lange periode seksueel contact met een jonge man onder bedreiging van geweld en/of door gebruikmaking van zijn overwicht als volwassene. De man wordt vervolgd voor het plegen van ontucht met minderjarigen, alleen of in vereniging, en poging tot het toebrengen van zwaar lichamelijk letsel. Het hof acht niet bewezen dat het feit is begaan in de periode dat het slachtoffer minderjarig was; het hof acht wel bewezen dat het feit in vereniging is begaan. Het hof veroordeelt de man voor het medeplegen van schennis van de eerbaarheid. Gezien het feit dat de man een lage virusload had ten tijde van het plegen van de delicten en gezien het feit dat andere risicoverho- gende factoren ontbraken, wordt hij voor de poging tot het toebrengen van zwaar lichamelijk letsel door het hebben van onbeschermd seksueel contact bij een positieve hiv-status vrijgesproken. Het hof legt een straf op van tien maanden waarvan vijf maanden voorwaardelijk met een proeftijd van twee jaar.

Hof Arnhem I3 februari 2006, LJN AVI57I, zaaknr. 2I-002178-05.

Hiv-5

S. heeft meerdere malen onbeschermde seks met jongens-prostituees in de leeftijd van I6 tot I8 jaar, terwijl hij hiv-positief is. Van zijn hiv-status wordt door het openbaar ministerie en de pers geen geheim gemaakt. De zaak wordt, vanwege het feit dat $S$. een bekende Nederlander is, breed uitgemeten in de pers. S. wordt vervolgd en de Rechtbank Den Bosch veroordeelt hem voor de seksuele delicten met minderjarigen en voor poging tot zware mishandeling door het hebben van onbeschermde seks bij een positieve hiv-status. In hoger beroep veroordeelt het hof S. voor ontucht met minderjarigen in de leeftijd van I6-I8 jaar en spreekt $S$. vrij van het toebrengen van zwaar lichamelijk letsel. Het louter hebben van onbeschermd seksueel contact bij een positieve hiv-status, zonder dat sprake is van risicoverhogende factoren, levert volgens het hof geen poging tot zware mishandeling op. Het hof is verder van mening dat de persoonlijke levenssfeer van $\mathrm{S}$. is geschonden door het naar buiten brengen van de hiv-status van S. door het openbaar ministerie. Het hof legt een gevangenisstraf van vifftien maanden op, waarvan vijf maanden voorwaardelijk, met een proeftijd van twee jaar. Het hof houdt bij het opleggen van de straf rekening met de schending van de persoonlijke levenssfeer van S.; zonder deze schending zou het onvoorwaardelijke deel van de straf twaalf maanden zijn geweest.

Hof Den Bosch i9 juli 2005, LJN AT9538, zaaknr. 20-004I89-04.

5 BESLISSINGEN ROND HET LEVENSEINDE

Palliatieve sedatie

Een arts-assistent dient een patiënt die stervende is morfine en dormicum toe. Hierna komt de patiënt te overlijden. De arts-assistent wordt vervolgd voor primair moord, subsidiar doodslag met strafver- 
zwarende omstandigheden (art. $288 \mathrm{Sr}$ ). Het hof spreekt de arts vrij van beide feiten. Het hof stelt dat het opzet of het voorwaardelijk opzet op de dood van de patiënt ontbreekt, aangezien de gebruikte middelen passend waren bij palliatieve sedatie en ook de hoeveelheid van de toegediende middelen niet excessief was. Het hof bevestigt hiermee het vonnis van de rechtbank en oordeelt hiermee in overeenstemming met de later in dat jaar te verschijnen Richtlijn palliatieve sedatie van de KNMG. Met deze uitspraak wordt palliatieve sedatie weer teruggebracht tot wat het is: normaal medisch handelen.

Hof Den Bosch I9 juli 2005, TvGR $2005 / 36$.

Hulp bij zelfdoding-I

Een maatschappelijk werker verleent bijstand aan een cliënt die aangeeft levensmoe te zijn en de wens te hebben om een eind aan zijn leven te maken. Hij verschaft de cliënt een boek waarin deze informatie kan vinden over het gebruik van medicatie om een einde aan het leven te maken en hij geeft een schriftelijke toelichting op het gebruik van verschillende voor het doel geschikte medicijnen. Daarnaast geeft hij de cliënt schriftelijk en mondeling instructies over de wijze waarop deze een forse dosis Tranxene en Depronal kan krijgen. Ten slotte levert de maatschappelijk werker de benodigde medicijnen, verkregen door een medicijnenruil, aan de cliënt, waarna de cliënt zich van het leven berooft. De maatschappelijk werker wordt vervolgd voor het verlenen van hulp bij zelfdoding en overtreding van artikel 2 lid 3 van de Wet op de geneesmiddelenvoorziening, het onbevoegd afleveren van geneesmiddelen. De rechtbank acht beide feiten bewezen en vermeldt daarbij dat de opvatting, dat van hulp bij zelfdoding geen sprake kan zijn als de verdachte niet aanwezig is bij de zelfdoding, onjuist is. De rechtbank verwijt de maatschappelijk werker dat hij had moeten weten dat het oordeel omtrent uitzichtloos lijden aan een arts was; hij had de hulp van een arts in moeten roepen. Het beroep op het ontbreken van materiële wederrechtelijkheid wordt verworpen. Het verweer dat de medicijnen oorspronkelijk door een arts waren voorgeschreven wordt eveneens verworpen. De rechtbank legt een gevangenisstraf van een jaar op. Met dit vonnis volgt de rechtbank HR 22 maart 2005, GJ 2005/6I (De Einder).

Rb. Alkmaar 7 december 2005, TvGR 2006/Io.
Hulp bij zelfdoding-2

Een vrouw wil zich van het leven beroven met een schietwapen. Tegen haar partner maakt zij melding van dit voornemen; tevens zegt zij dat zij geen geld heeft om het wapen te kopen. $\mathrm{Zij}$ is van plan om het geld te verdienen door zich te prostitueren. De man wil voorkomen dat zij dit moet doen om zich van het leven te beroven, dus verkoopt hij haar dvd-speler en geeft het geld aan haar. Bovendien geeft hij haar een pinpas zodat zij de rest van het benodigde geld kan pinnen. Nadat de vrouw het wapen heeft gekocht vult de man het wapen met patronen. Hierna berooft de vrouw zich van het leven. De man wordt vervolgd voor hulp bij zelfdoding. Het beroep op psychische overmacht wordt door de rechtbank niet gehonoreerd. De rechtbank veroordeelt de man tot zes maanden gevangenisstraf voorwaardelijk, met een proeftijd van twee jaar. Het wapen wordt onttrokken aan het verkeer.

Rb. Leeuwarden 20 juni 2006, LJN AX8950, zaaknr. I7/885084-05 VEV.

6 OVERIG

\section{Tandarts}

Een tandarts sluit een verzekering af voor arbeidsongeschiktheid. De tandarts krijgt daarna een autoongeval en verliest daarbij een vinger. Als de tandarts de uitkering van de verzekering ten bedrage van ruim

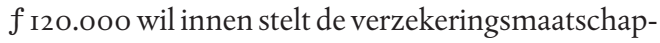
pij een onderzoek in. Hieruit blijkt dat de amputatie van de vinger een scherpe amputatie is. Verder blijkt er in het weefsel van de vinger lidocaine, een lokaal verdovingsmiddel, te zitten. Hierdoor wordt duidelijk dat de tandarts zijn eigen vinger heeft geamputeerd om zodoende de verzekeringspenningen te kunnen innen. De tandarts wordt vervolgd voor het valselijk opmaken van een verklaring (fraude). De rechtbank veroordeelt hem tot een gevangenisstraf van zes maanden voorwaardelijk, met een proeftijd van twee jaar, en een taakstraf van 240 uur en een geldboete van $€ 25$.0oo, vervangende hechtenis 260 dagen.

Rb. Zutphen 2 november 2006, LJN AU5333, zaaknr. 06/o86025-oo. 


\section{Bedreiging in een Bopz-instelling}

Een man die met een Bopz-maatregel in een psychiatrisch ziekenhuis verblijft, bedreigt een arts en twee verpleegkundigen met een (ingeklapt) zakmes. De hulpverleners voelen zich door de houding en het gedrag van de man zodanig bedreigd dat zij van mening zijn dat zij niet opgewassen zijn tegen zijn gedrag. Daarnaast bedreigt de man ook nog een vrouw en haar twee kinderen en gijzelt hen in hun woning. De man wordt door het hof schuldig bevonden aan bedreiging met een misdrijf, waardoor de veiligheid van personen in gevaar wordt gebracht (tegen de hulpverleners), voor bedreiging met een misdrijf tegen het leven gericht en voor wederrechtelijke vrijheidsberoving (tegen de vrouw en haar kinderen). In tegenstelling tot de rechtbank acht het hof de bedreiging met een misdrijf tegen het leven van de hulpverleners gericht niet bewezen. Het hof vernietigt het vonnis en legt, evenals de rechtbank, tbs met dwangverpleging op.

Hof Den Haag 3i januari 2006, LJN AVo849, zaaknr. 2200371605.

\section{Vrijheidsberoving}

Een 64-jarige man heeft een psychotische echtgenote. Zijn zoon raakt eveneens in een acute psychose. De man probeert zijn psychotische zoon in bedwang te houden door hem met behulp van riempjes te fixeren op een stoel. Hierbij bindt hij de handen van de jongen op de rug. De man wordt vervolgd voor wederrechtelijke vrijheidsberoving. De man bekent de vrijheidsberoving en voert aan dat hij in een noodtoestand verkeerde omdat hij moest wachten op zorg. De huisarts van de familie was namelijk op cursus en de plaatsvervanger had alleen slaaptabletten aangeboden. Als de jongen enkele dagen later is opgenomen, verblijft hij vier dagen en nachten in een isoleercel. Naast de vrijheidsberoving wordt de man ten laste gelegd dat hij zijn vrouw zou hebben mishandeld door haar in de pink te bijten en zijn psychotische zoon door hem de nodige medicatie te onthouden. De man ontkent de hem ten laste gelegde mishandelingen van zijn vrouw en zoon. Voor de mishandeling van de vrouw is geen bewijs behalve de weinig coherente verklaring van de vrouw zelf. Voor de mishandeling van de zoon is geen bewijs behoudens een verklaring van een dochter en schoonzoon, die het verhaal van een ander hebben gehoord. De rechtbank acht de wederrechtelijke vrijheidsberoving bewezen. Het beroep op noodtoestand wordt afgewezen; de rechtbank is van mening dat de man nog voldoende andere mogelijkheden had om op te treden, zoals het inroepen van professionele hulp. De rechtbank legt een gevangenisstraf van vier maanden voorwaardelijk op, met een proeftijd van twee jaar en met verplicht reclasseringscontact en verplicht onderhouden van contact met de ambulante forensische psychiatrie Noord-Nederland. Misschien is dit wel een erg zware straf op het uitblijven van zorg.

$\mathrm{Rb}$. Groningen 15 augustus 2006, LJN AY6233, zaaknr. 18/670168-o6.

7 TEN SLOTTE

In de kroniek rechtspraak strafrecht valt het meest op dat er het afgelopen jaar een relatief groot aantal zaken is geweest dat draaide om strafrechtelijk verwijtbaar handelen door hulpverleners. Hulpverleners worden vaker beoordeeld naar strafrechtelijke maatstaven; ook hulpverleners die bij het verlenen van acute hulp een inschattingsfout maken worden strafrechtelijk getoetst. Het openbaar ministerie lijkt daarbij nog op zoek naar de grens tussen wat wel en niet verwijtbaar is. De rechter geeft de hulpverlener, mijns inziens terecht, iets meer ruimte dan het openbaar ministerie om beslissingen te nemen en daarbij ook fouten te maken zonder dat dit leidt tot een strafrechtelijk verwijt. De grens voor strafrechtelijk verwijtbaar handelen wordt ook gezocht als het gaat om het handelen van alternatieve genezers. Deze ontwikkeling is al enige tijd gaande en is zeker nog niet ten einde; het Hof Leeuwarden zal zich eind dit jaar een oordeel vormen in de Eye 4 care-zaak.

Op bepaalde fronten van het gezondheidsstrafrecht is weer rust gekomen. Met de uitspraak in de Savanna-zaak lijkt de Hoge Raad weer de bekende lijn te volgen. Ook de hiv-jurisprudentie en de jurisprudentie betreffende handelen rond het levenseinde lijkt zo langzamerhand uitgekristalliseerd. De Richtlijn palliatieve sedatie van de KNMG heeft hieraan een grote impuls gegeven. De ruimte voor een hulpverlener om te bepalen wat 'professioneel medisch handelen aan het einde van het leven' is wordt daarmee weer wat groter. Mijns inziens is dit een goede ontwikkeling. 